\title{
An Empirical Model of Road Traffic Noise on Heterogeneous Traffic Situation
}

\author{
Muralia Hustim ${ }^{1, *}$ and Isran M. Ramli ${ }^{2}$ \\ ${ }^{1}$ Senior Lecturer, Department of Environmental Engineering, Universitas Hasanuddin, \\ Indonesia \\ ${ }^{2}$ Associate Professor, Department of Civil Engineering, Universitas Hasanuddin, Indonesia
}

\begin{abstract}
The motorcycle domination on heterogeneous traffic situation in many cities in developing countries including Indonesia leads to the decreasing of environment qualities such noise pollution. Regarding the road traffic noise (RTN) pollution, this paper attempts to develop an empirical model for a RTN prediction model. The model based on a motorcycle unit as reference unit to consider flow rate of the road traffic which dominated by motorcycles. The study collected the RTN data such volume of each vehicle types, i.e., motorcycle; light vehicle; and high vehicle, and the noise level on the forty arterial roads in Makassar, Indonesia. The survey methods based on the traffic count method and the measurement noise level using a video camera and a sound level meter, respectively. We collected data during ten minutes of each one-hour period of each road. The empirical relationship models between the noise level and the traffic volume based on the motorcycle unit were developed using various types of regression models. The results showed that the polynomial model is more significant than the other models. We expected that the model provides a basic RTN prediction model in order to simulate some measures of the traffic management system in reducing the RTN level in Makassar City.
\end{abstract}

\section{INTRODUCTION}

Nowadays, the rapidly growth of the motorcycle population in many cities in developing countries has been generating traffic problems such traffic congestion, noise and air pollution $[1,2]$. Addressed to road traffic noise emission, in particular for the heterogeneous traffic condition, Hustim et.al [1] has conducted a survey for road traffic noise in Makassar City in Indonesia. Hustim et all have focused to the effect of horn on noise level [2]. Also, Hustim et all [2] developed the road traffic noise model prediction for heterogeneous traffic condition in Makassar City using ASJ-RTN Model approach.

In order to contribute in this research field, this paper attempts to develop an empirical model for a RTN prediction model. The model based on a motorcycle unit as reference unit

\footnotetext{
Corresponding author: $\underline{\text { muraliahustim } @ \text { yahoo.com }}$
} 
to consider flow rate of the road traffic which dominated by motorcycles. The rest of this paper is presented as follows. The next section presents the methodology, then, it is followed by result presentations. Finally, the paper provides a conclusion.

\section{THE STUDY METHODS}

\subsection{The Survey Location}

The present study has conducted a road traffic noise (RTN) which consist of noise level, traffic volume, and vehicle speed. The survey located at 40 roadsides in Makassar City, Indonesia. Table 1 presents the characteristics of the roads such as length, lane, width, and the distance between the point measurement of the noise level measurement and the centerline of the roads.

\subsection{Measurement of noise level}

The measuring point was set at a position with the distance of $1.0-3.0 \mathrm{~m}$ from the road edge and the height of $1.2 \mathrm{~m}$ above the ground. A-weighted sound pressure level (LAeq, LA05, LA50, and LA95) of RTN was measured in ten minutes every one hour from 8:00 a.m. through 5:10 p.m.; ten data for each noise index were collected at each roadside.

Table 1 The Road Characteristics

\begin{tabular}{|c|c|c|c|c|c|c|}
\hline \multirow{3}{*}{ No } & \multirow{3}{*}{ Road } & \multicolumn{5}{|c|}{ Road characteristic } \\
\hline & & Length & Lane & Width & Med & $d$ \\
\hline & & $(\mathrm{km})$ & & $(\mathrm{m})$ & (m) & (m) \\
\hline 1 & R36. Jl. Dg. Tata & 1.637 & 2 & 8.00 & 0.0 & 1.50 \\
\hline 2 & R02. J1. Andi Tonro & 1.287 & 2 & 5.00 & 0.0 & 1.50 \\
\hline 3 & R03. J1. Kumala & 1.425 & 2 & 4.50 & 0.0 & 2.00 \\
\hline 4 & R05. Jl. Kakatua & 0.502 & 2 & 10.60 & 0.0 & 1.00 \\
\hline 5 & R06. Jl. Gagak & 0.303 & 2 & 10.00 & 0.0 & 1.20 \\
\hline 6 & R11. J1. Sulawesi & 1.212 & 2 & 10.00 & 0.0 & 1.00 \\
\hline 7 & R15. J1. G. Bulusaraung & 0.618 & 2 & 9.50 & 0.0 & 1.25 \\
\hline 8 & R31. J1. St. Hasanuddin & 0.858 & 2 & 9.00 & 0.0 & 1.50 \\
\hline 9 & R23. J1. Antang Raya & 1.500 & 2 & 4.00 & 0.0 & 1.50 \\
\hline 10 & R24. J1. Borong Raya & 1.800 & 2 & 4.50 & 0.0 & 2.00 \\
\hline 11 & R25. J1. Batua Raya & 1.300 & 2 & 5.00 & 0.0 & 1.50 \\
\hline 12 & R26. J1. Abd. Dg. Sirua & 3.727 & 2 & 6.00 & 0.0 & 1.00 \\
\hline 13 & R35. J1. Cendrawasih & 5.806 & 2 & 6.50 & 0.0 & 1.00 \\
\hline 14 & R37. J1. Malengkeri & 1.565 & 2 & 5.00 & 0.0 & 1.20 \\
\hline 15 & R29. J1. Sungai Saddang & 1.170 & 2 & 11.00 & 0.0 & 1.10 \\
\hline 16 & R34. J1. Cakalang & 0.445 & 2 & 11.00 & 0.0 & 1.10 \\
\hline 17 & R38. J1. Rappocini & 1.414 & 2 & 4.00 & 0.0 & 1.20 \\
\hline 18 & R01. J1. St.Alauddin & 3.826 & 4 & 17.60 & 0.0 & 1.00 \\
\hline 19 & R33. J1. Bandang & 0.956 & 4 & 15.00 & 2.0 & 1.50 \\
\hline 20 & R13. Jl. Ahmad Yani & 0.690 & 4 & 13.60 & 0.0 & 1.80 \\
\hline 21 & R04. J1. Ratulangi & 2.067 & 4 & 12.56 & 0.0 & 2.00 \\
\hline 22 & R07. Jl. Rajawali & 0.835 & 4 & 12.50 & 0.0 & 1.00 \\
\hline
\end{tabular}




\begin{tabular}{llrllll}
23 & R16. Jl. Mesjid Raya & 1.240 & 4 & 15.00 & 0.0 & 1.20 \\
24 & R32. J1. Tentara Pelajar & 0.891 & 4 & 14.00 & 1.4 & 1.50 \\
25 & R08. J1. Haji Bau & 0.622 & 4 & 14.50 & 0.0 & 1.50 \\
26 & R09. J1. Penghibur & 1.240 & 4 & 10.80 & 0.0 & 1.00 \\
27 & R14. J1. Jend. Sudirman & 1.339 & 4 & 17.66 & 0.0 & 1.20 \\
28 & R30. J1. Arief Rate & 0.321 & 4 & 18.00 & 0.0 & 3.00 \\
29 & R10. J1. Nusantara & 1.707 & 4 & 12.40 & 0.3 & 1.10 \\
30 & R12. J1. Riburane & 0.232 & 4 & 18.30 & 0.7 & 3.00 \\
31 & R17. J1. G。 Bawakaraeng & 1.073 & 4 & 14.70 & 0.0 & 1.00 \\
32 & R18. J1. Veteran Utara & 2.641 & 4 & 15.00 & 2.0 & 1.00 \\
33 & R19. J1. Veteran Selatan & 1.878 & 4 & 15.00 & 2.0 & 1.00 \\
34 & R21-1. Jl. U.Sumoharjo & 4.506 & 4 & 16.00 & 2.5 & 2.00 \\
35 & R21-2. J1. U.Sumoharjo & 4.506 & 4 & 17.00 & 2.5 & 1.10 \\
36 & R27. J1. Boelevard & 1.670 & 4 & 16.00 & 2.0 & 1.00 \\
37 & R28. J1. Hertasning Raya & 1.544 & 4 & 12.36 & 4.5 & 1.00 \\
38 & R20. J1. AP. Pettarani & 4.373 & 6 & 20.00 & 2.2 & 1.20 \\
39 & R22-1. Jl. P.Kemerdekaan & 11.970 & 6 & 21.00 & 3.0 & 1.00 \\
40 & R22-2. J1. P.Kemerdekaan & 11.970 & 6 & 16.00 & 2.5 & 1.00 \\
\hline
\end{tabular}

\subsection{Investigation of traffic volume and the speed of vehicles}

The traffic volume investigation was carried out during the traffic noise measurement. By using a manual counter, the surveyors individually counted the numbers of heavy vehicle $(\mathrm{H})$, light vehicle (L), and motorcycle (MC) were counted. Figure 1 shows the set location of the noise level measurement and visualizes the traffic noise measurement in the roadside.

\subsection{The empirical model approach for the road traffic noise prediction}

The present study adopted some various regression models such as linear model, exponential model, logarithmic model, and polynomial model. In this regard, the traffic noise level become a dependent variable, while the traffic volume based on motorcycle unit is the independent variable. 

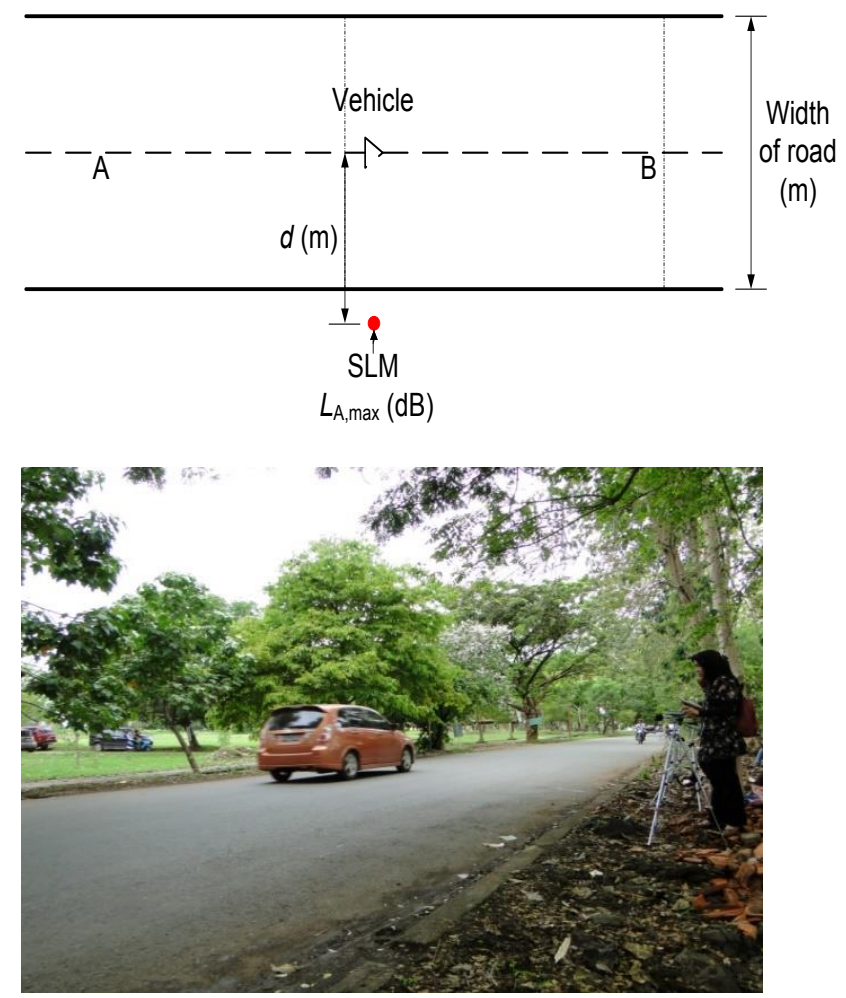

Fig. 1. The set location of the noise level measurement in the roadside

\section{RESULTS AND DISCUSSION}

\subsection{Noise Level}

It can be found in the fluctuations of noise levels, LAeq, LA05, LA50, and LA95 for 10 minutes from 8 a.m. to 5 p.m. that noise levels are almost constant through the measurement times ( 8 a.m. to 5 p.m.); the difference between ten LAeq s during the measurement hours is within $3 \mathrm{~dB}$ in all roads. In further, 40 data of LAeq, day for each road are within $68 \mathrm{~dB}$ and $77 \mathrm{~dB}$, and the arithmetic average of them is $73 \mathrm{~dB}$. This shows that all the areas along the surveyed roads are very noisy, and if the Environmental Quality Standard for Noise in Indonesia shall be applied, more than $90 \%$ of the areas exceed the standard even though the highest value of the Standard $(70 \mathrm{~dB})$ is adopted. 


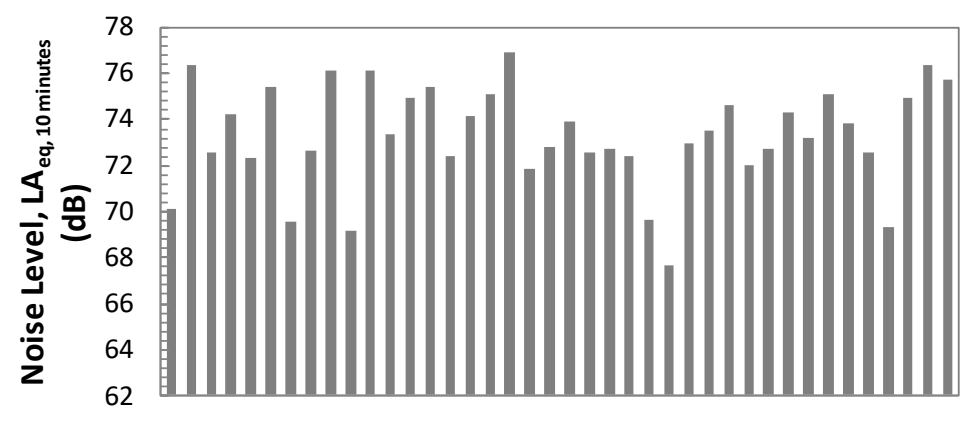

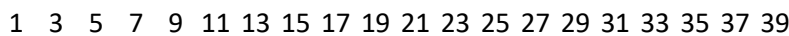

The Road Points of Measurements

Fig. 2. The Noise Level Measurement Results

\subsection{Traffic conditions}

The survey results show that the total traffic volumes are 289 to 649 , and 196 to 1445 , and 1366 to 2115 vehicles/10min. for two-lane road, four-lane road, and six-lane road, respectively. In further, the percentages of heavy vehicle $(\mathrm{H})$, light vehicle $(\mathrm{L})$, and motorcycle (MC) are, on average, $1.6 \%, 31.5 \%$, and $66.9 \%$, respectively. This shows that motorcycle commands an absolute majority of traffics in Makassar City. The average speed of vehicles is between $25 \mathrm{~km} / \mathrm{h}$ and $31 \mathrm{~km} / \mathrm{h}$; this might show that all the roads are congested with traffic, and consequently the speed of vehicles is limited at all roads. The numbers of horns of vehicles widely change from 25 times/10min. to 125 times/10min.

Regarding the traffic volume condition where the motorcycle is the dominant traffic, the present study proposed the traffic volume based on the equivalent motorcycle unit (emu). The conversion of the others vehicle types to the motorcycle unit based on the equivalency traffic volume curve as in Figure 5. Therefore, the relationship calculation between the traffic noise level and the traffic volume based on the traffic volume which has motorcycle unit.

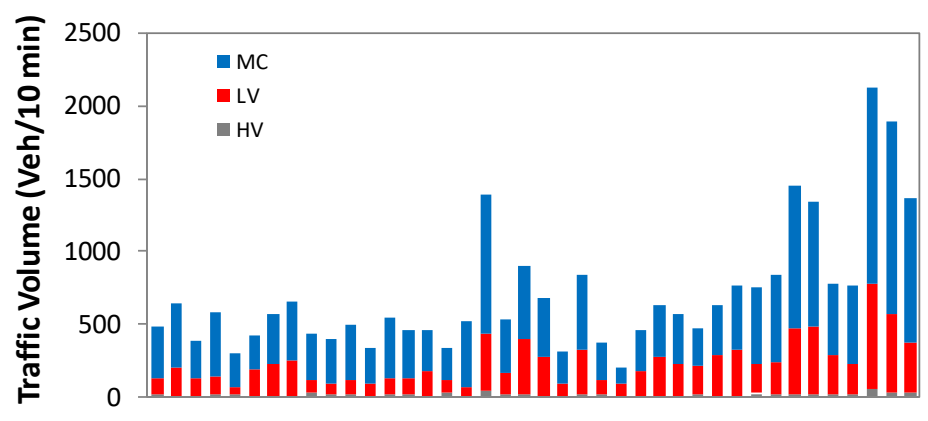

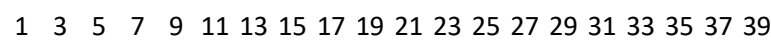

The Road Points of Measurements

Fig. 3.The Traffic Volume in the Study Location 


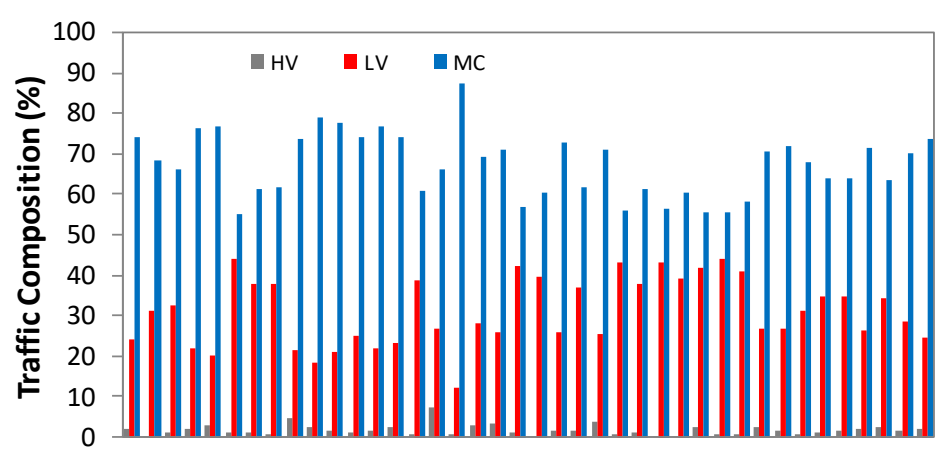

$\begin{array}{llllllllllllllllllll}1 & 3 & 5 & 7 & 9 & 11 & 13 & 15 & 17 & 19 & 21 & 23 & 25 & 27 & 29 & 31 & 33 & 35 & 37 & 39\end{array}$

The Road Points of Measurements

Fig. 4. The Traffic Composition in the Study Location

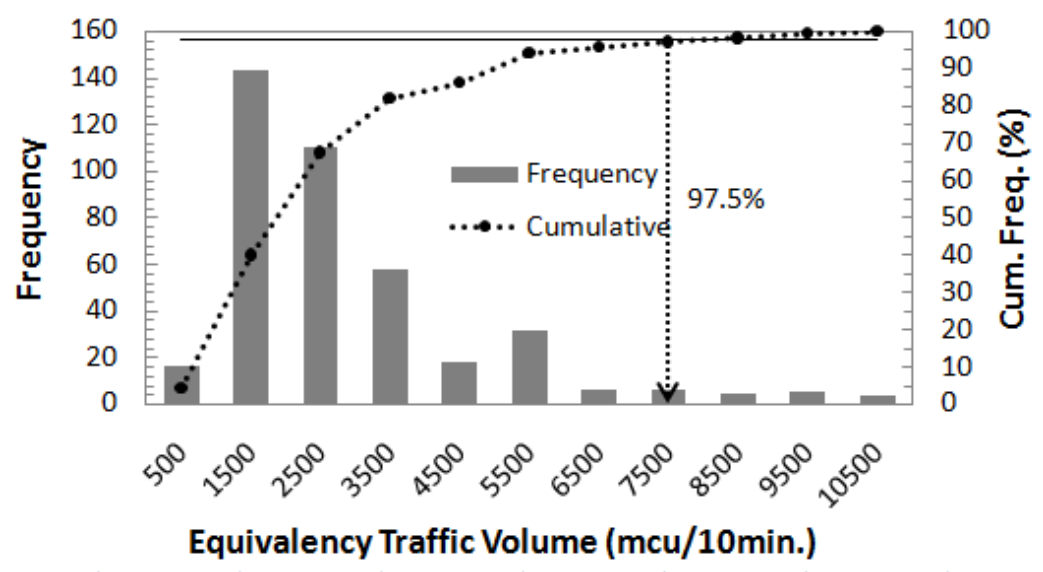

Fig. 5. The Equivalency Traffic Volume in the Study Location

\subsection{The Estimation Results of the Traffic Noise Empirical Model}

Figure 6 shows the calculation results of the four various models approach, such as the linear model, the exponential model, the logarithmic, and the polynomial model, for the traffic noise level based the motorcycle unit. In addition, Figure 7 shows the results of the model validation for the four various models.

Figure 6 shows that the polynomial regression approach has the highest determinant coefficient (R2) value, i.e., 0,9329. This result is in line with the validation result of the model by using the correlation analysis between the observed results and the model calculation results. 

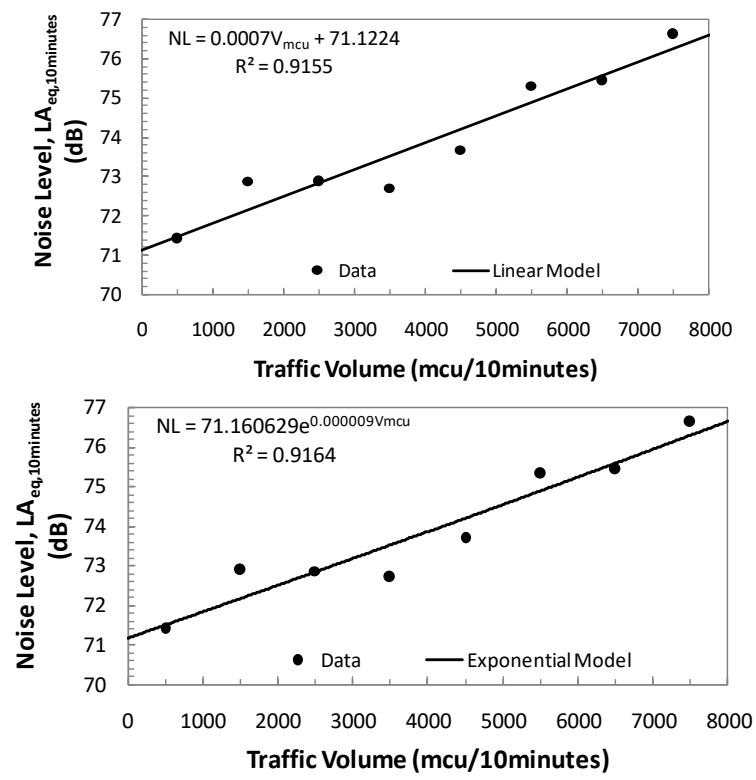

a. The linear model

b. The exponential model
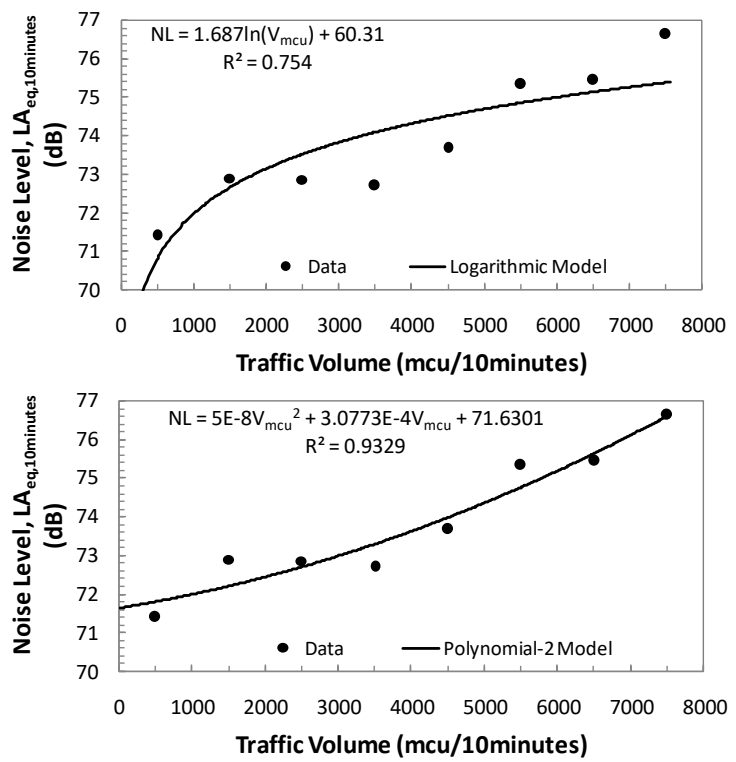

c. The logarithmic model

d. The polynomial model

Fig. 6. The Road Traffic Noise Models 

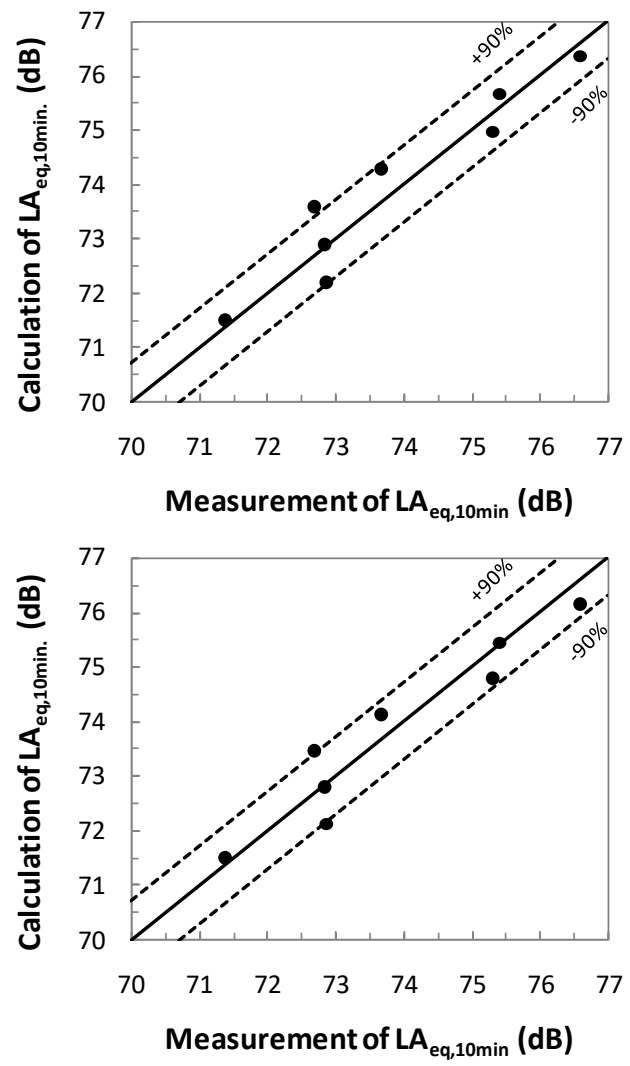

a. The linear model b. The exponential model 

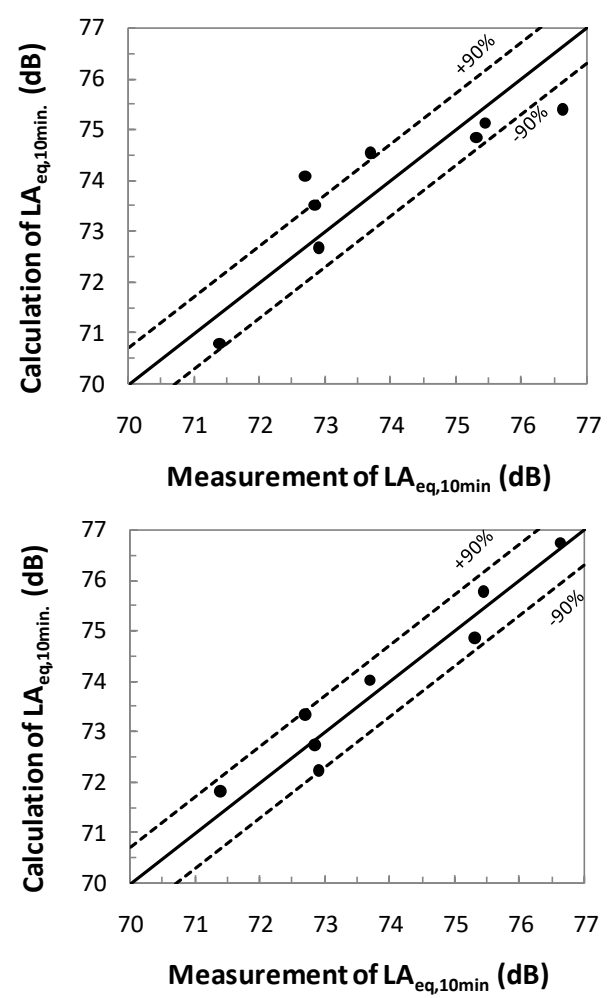

c. The logarithmic model

d. The polynomial model

Fig. 7. Validation of the Road Traffic Noise Models

\section{CONCLUSSION}

The influence of the majority motorcycle composition in the heterogeneous traffic in Makassar City, Indonesia, to the road traffic noise level has been explored in this study. Through utilization of some various regression types such as linear, exponential, logarithmic, and polynomial models, the empirical relationship between the road traffic noise level and the traffic volume which based on motorcycle unit, was developed.

The polynomial regression model approach has the highest the determinant coefficient among the others models. However, all the regression models have good acceptance level for their determinant coefficient. The results lead to the implication that the motorcycle unit approach in converting the traffic volume into the model has influence significantly the road traffic noise level in the roads.

\section{References}

1. M. Hustim., K. Anai, Fujimoto, K., Survey on Road Traffic Noise in Makassar City in Indonesia: Effect of Horn on Noise Level. Proceeding of the 40th Conference of Architectural Institute of Japan, Kyushu Branch (2011).

2. Hustim, M., Fujimoto, K., Road Traffic Noise under Heterogeneous Traffic Condition in Makassar City, Indonesia. Journal of Habitat Engineering and Design, 4, 1, pp. 109 118 (2012). 